Int. J. Dev. Biol. 62: 465-471 (2018)

https://doi.org/10.1387/ijdb.180056cr

\title{
Reservoirs for repair? Damage-responsive stem cells and adult tissue regeneration in Drosophila
}

\author{
SILVIA SCHWARTZ and CHRISTA RHINER* \\ Champalimaud Neuroscience Programme, Champalimaud Institute for the Unknown, Lisbon, Portugal
}

\begin{abstract}
Adult stem cells in mammals are important for normal tissue renewal (homeostasis) and regeneration after injury. In the past ten years, different types of homeostatic adult stem cells have also been identified in the genetically accessible fruit fly (Drosophila melanogaster), among which intestinal stem cells have taken centre stage. Recent studies provide evidence that adult fly tissues may also harbor quiescent stem cells, which can enter cell cycle upon injury to regenerate compromised tissue. Such damage-responsive stem cells have been described in flight muscles, the adult brain and in a narrow region of the fly hindgut. Strikingly, many mammalian tissues have also been shown to maintain quiescent, but regeneration-competent, stem cells. However, little is known about the injury-induced signals that lead to their activation. Here, we provide a brief overview of active and damage-responsive adult stem cells in the fruit fly and focus on injurydependent signalling events. We highlight the potential of Drosophila to model damage-induced stem cell activation to deepen our molecular understanding of how dormant stem cells can be efficiently recruited for tissue repair after injury.
\end{abstract}

KEY WORDS: stem cell regulation, damage-responsive stem cell, tissue regeneration, Drosophila

\section{Introduction}

Mammals, including humans, have a limited regenerative capacity, but display two critical mechanisms which allow them to preserve tissue morphology and functionality after development has ceased: 1. Physiological cell turnover, which takes place as a daily routine (e.g. renewal of intestinal lining) and 2. tissue regeneration, occurring in response to external insults that cause tissue damage. How animals cope with damage to restore tissue integrity varies across the animal kingdom and can even differ among tissues within the same species. The main strategies involve tissue rearrangement, de- or trans-differentiation of committed cells close to the injury site or - as discussed here - the activation of stem/ progenitor cells (Sánchez Alvarado and Tsonis, 2006; Poss, 2010).

Physiological turnover, along with well-understood blood regeneration in humans, critically depends on adult stem cells, which are undifferentiated, long-lived cells embedded in most tissues (Raff, 2003; Fuchs and Chen, 2013). In general, stem cell divisions lead to the generation of one daughter cell that maintains stem cell fate (self-renewal), while the other daughter cell proceeds through differentiation. Thanks to the application of better lineage tracing tools and improved stem cell markers, there is increasing evidence in rodents that numerous tissues contain both actively cycling and quiescent (non-dividing) stem cells (Visvader and Clevers, 2016). The experimental data suggests that constitutively active (also called "professional") stem cells are responsible for normal tissue turnover, while pools of quiescent stem cells, embedded in different locations, are exclusively mobilized upon injury. Such regenerationcompetent "reserve" stem cells have been described in the blood, the skin, the stomach and recently also the intestine of rodents (Ito et al., 2005; Wilson et al., 2008; Tian et al., 2011; Lu et al., 2012; Yan et al., 2012; Leushacke et al., 2017; Suh et al., 2017). Insight into how damage-responsive stem cells are maintained inactive and called into action upon tissue damage is of broad relevance to understand their regenerative properties, but also their potential susceptibility to contribute to cancer formation in case of failing control mechanisms (Leushacke et al., 2017).

Comparative analyses, aimed at understanding differences between quiescent and active stem cells, have revealed that inactive stem cells are characterized by a low metabolic state and high resistance to stress (hypoxia). Quiescent hematopoietic stem

Abbreviations used in this paper: FCS, follicular stem cell; GSSC, gastric stem cell; HGP, hindgut progenitor; HSC, hematopoietic stem cell; ISC, intestinal stem cell; MSC, muscle stem cell; NP, neural progenitor; OGSC, ovary germline stem cell; RNSC, renal stem cell.

\footnotetext{
*Address correspondence to: Christa Rhiner. Champalimaud Neuroscience Programme, Champalimaud Institute for the Unknown, Lisbon 1400-038, Portugal. E-mail: christa.rhiner@ research.fchampalimaud.org - web: rhinerlab.org - (iD) https://orcid.org/0000-0001-7577-8042
} 
cells (HSCs), for example, express high levels of hypoxia inducible factor $1 \alpha(\mathrm{HIF} \alpha)$. In the absence of HIF $\alpha$, HSCs exit quiescence and are depleted over time (Takubo et al., 2011), demonstrating that high HIF $\alpha$ levels are important to maintain quiescence. The non-dividing state of stem cells is also actively enforced by the expression of cell cycle inhibitors (Cheng et al., 2000; Suh et al., 2017) and their chromatin is generally kept in a flexible conformation to allow different lineage choices once activated (Cheung and Rando, 2013). In vivo, the presence of inactive stem cells is experimentally detectable based on long-term retention of DNA labels in contrast to cycling stem cells. Apart from these features, we still understand little about the injury-dependent molecular mechanisms that drive dormant stem cells into a regenerative mode.

The fruit fly Drosophila melanogaster has proven an excellent model organism to study tissue regeneration and stem cell control. Because of its short life cycle, a non-redundant genome and the availability of numerous sophisticated genetic tools, Drosophila is ideal to perform rapid in vivo screens (RNAi or mutagenesis) to identify key genes involved in complex processes and manipulate their function in a tissue-specific manner. Research on regeneration in wing imaginal discs (developing epithelia) has led to the identification of key injury signals (e.g. reactive oxygen species), stress signalling modules (JNK/p38/Unpaired) and ultimately pathways involved in regenerative growth (Wg/Wnt, Myc, JAK-STAT) (Bosch et al., 2005; Smith-Bolton et al., 2009; Santabárbara-Ruiz et al., 2015; Fogarty et al., 2016).

In the adult fly, tissue regeneration has been mainly studied in the context of intestinal repair based on stem cells, as discussed in the next section. However, adult fly tissues are also equipped with alternative mechanisms to compensate for tissue loss independent of stem cells. Remarkably, cell ablation in follicular tissues in the fly ovary (Tamori and Deng, 2013) or the epidermis (Losick et al., 2013) induces post-mitotic cells close to the injury to re-enter the endocycle, which leads to an increase in cell size that compensates for lost cell mass. This process, termed compensatory cellular hypertrophy (Tamori and Deng, 2013), represents an evolutionarily conserved strategy to maintain tissue homeostasis in the absence of cell divisions (Losick et al., 2016).

Overall, somatic tissues in the adult fly have long been viewed as postmitotic and relatively stable. This traditional view has strongly changed with the identification of adult somatic stem cells, mainly the versatile intestinal stem cells. Recent studies in Drosophila have also identified quiescent progenitor cells in several tissues, which participate in tissue regeneration after injury. Here, we evaluate in detail the current findings on these newly discovered damageresponsive progenitors and highlight the possibility to study the molecular underpinnings of damage-induced stem cell activation in Drosophila.

\section{Somatic stem cells in Drosophila}

Although this review focuses on somatic stem cells in Drosophila, we will start with a paragraph on cycling germline stem cells, which have been instrumental to uncover conserved principles of stem cell proliferation in the context of a niche (Greenspan et al., 2015; Fuller and Spradling, 2007). In adult female flies, 2-3 ovary germline stem cells (OGSCs) can be found at the tip of each ovariole in the ovary (Fig. 1). OGSCs are constantly dividing within a well-defined niche, which provides stemness factors and anchoring molecules
(Fuller and Spradling, 2007). OGSCs dividing asymmetrically yield a daughter cell that maintains interaction with the niche (self-renewal), whereas the other daughter cell, which is displaced away from the niche, initiates a differentiation program. Stem cells are normally replaced by symmetric division of other OGSCs, but differentiated progeny is also able to de-differentiate and revert to OGSCs if all germline stem cells are lost (Kai and Spradling, 2004).

\section{Homeostatic stem cells}

Adult fly tissues contain several cycling epithelial stem cells including follicular stem cells (female germline), cyst stem cells (male germline), gastric stem cells, intestinal stem cells and renal stem cells. We will briefly discuss all these "homeostatic" stem cell types, however, only intestinal stem cells have been extensively studied with regards to proliferative control, both under resting and stress conditions.

Intestinal stem cells (ISCs) are not located in a fixed niche, but rather distributed throughout the fly midgut (Fig. 1), which is similar to the small intestine in mammals. The midgut contains approximately $800-1000$ ISCs that divide regularly to renew nutrient absorbing enterocytes or hormone producing enteroendocrine cells. Lineage tracing experiments have shown that ISC activity leads to renewal of the midgut tissue within two weeks, although turnover is lower in males and young flies (Hudry et al., 2016). Since the discovery of ISCs in 2006 (Ohlstein and Spradling, 2006; Micchelli and Perrimon, 2006), a detailed understanding of how positive and negative feed-back loops coordinate enterocyte turnover and ISC proliferation has been gained. ISCs have also been extensively studied in the context of intestinal damage. Homeostatic ISC proliferation is regulated by various positive and negative feed-back loops via signals emanating from enterocytes, visceral muscles, trachea and hemocytes, which serve to coordinate turnover of differentiated cells with ISC cycling.

A detailed review of pathways regulating ISC divisions can be found elsewhere (Naszai et al., 2015; Guo et al., 2016). Here, we will only highlight selected studies, which have revealed injuryinduced activation of key signalling pathways that are required for regeneration.

Initial studies established that damage to the midgut - induced by chemicals or bacterial infection - triggers JNK stress signalling and results in cytokine secretion (Unpaired/IL6 ligands) from affected enterocytes. Released Unpaired ligands diffuse and bind to Dome/IL-6-like receptors present on ISCs leading to activation of JAK/STAT signalling (Biteau et al., 2008; Jiang et al., 2009). The induction of JAK/STAT in ISCs promotes their rapid proliferation. A recent study by the Perrimon lab showed that reactive oxygen species (ROS), which specifically rise in zone of tissue damage or infection and are known to trigger regeneration (Lee et al., 2013; Hochmuth et al., 2011), can activate newly identified redox-sensitive cation channels on ISCs resulting in calcium influx (Xu et al., 2017). Ras/MAPK and EGFR signaling were identified as most relevant pathways to mediate ISC division downstream of increased cytosolic calcium based on RNAi of a set of candidate genes (Xu et al., 2017).

Moreover, elevated levels of Wg/Wnt signalling in ISCs play an important role in midgut regeneration. In2012, Cordero et al., showed that injury leads to secretion of $\mathrm{Wg}$ from enteroblasts and that this inducible source of $\mathrm{Wg}$ represents an essential injury signal to drive accelerated ISC proliferation (Cordero et al., 2012). Subsequent RNAseq analyse of sorted intestinal cells by the Edgar and Buchon 
labs confirmed the damage-induced upregulation of Wg transcripts in enteroblasts (Dutta et al., 2015). Genetic blockage of either Wg signalling or the downstream induction of dMyc prevented injuryinduced proliferation of ISCs (Cordero et al., 2012). Interestingly, Wg-signaling also plays a crucial role in damage-responsive ISCs in the mouse intestine (Suh et al., 2017). This recent study describes how intestinal damage by irradiation (IR) leads to HIF-dependent induction of specific Wntgenes that carry multiple hypoxia response elements. The authors show that the resulting $\mathrm{Wg}$ pathway activity in ISCs is required for their activation since knock-out of $\beta$-catenin in ISCs abrogates their IR-induced exit of quiescence.

Besides the role of secreted factors, cell adhesion molecules have also emerged as dynamic regulators of the regenerative response in ISCs. When looking carefully at the morphology of dividing ISCs after injury, Zhai and colleagues observed that stem and daughter cells formed an extensive cellular interface after division, while dividing stem cells under physiological conditions showed little contact of cell membranes (Zhai et al., 2017). Further analyses based on sequence data confirmed that this tight apposition of stem and daughter cell was dependent on injury-induced upregulation of adhesion molecules such as E-cadherin, $\beta$-catenin and Connectin, which promotes an extensive signalling interface between Delta ligands on ISCs and Notch receptors on the daughter cell. The resulting boost of Notch signalling allows daughter cells to sprint through differentiation to rapidly supply the midgut with new enterocytes (Zhai et al., 2017). Although we limit our discussion to the regenerative context, it is important to note that most of the above-described pathways have also been found to play a role in homeostatic ISC proliferation, but the signalling levels or ligand sources required may differ.

The foregut is located anteriorly to the midgut and consists of the esophagus, crop and cardia (Fig. 1). The crop serves to store food and the cardia acts as a gastric valve, which regulates food passage to the crop and the anterior midgut. In 2011, Hou and colleagues identified multipotent progenitors, termed gastric stem cells (GSSCs), in the area of the cardia at the foregut/midgut junction (Singh et al., 2011). Using lineage-tracing methods, Singh et al., demonstrated that dividing Wg-expressing GSSCs give rise to differentiated cells in the crop, esophagus and the anterior midgut, where they are likely to replace cells undergoing apoptosis. Moreover, overexpression and loss-of-function experiments suggest that Wg signaling is essential for GSSCs maintenance and self-renewal, whereas JAK-STAT activity promotes proliferation and the Hedgehog pathway ensures differentiation of gastric stem cells (Singh et al., 2011). The precise cellular sources of ligands still remain to be shown since the majority of genetic manipulations were conducted with ubiquitous drivers.

Homeostatic stem cells have also been described in the Malpi-

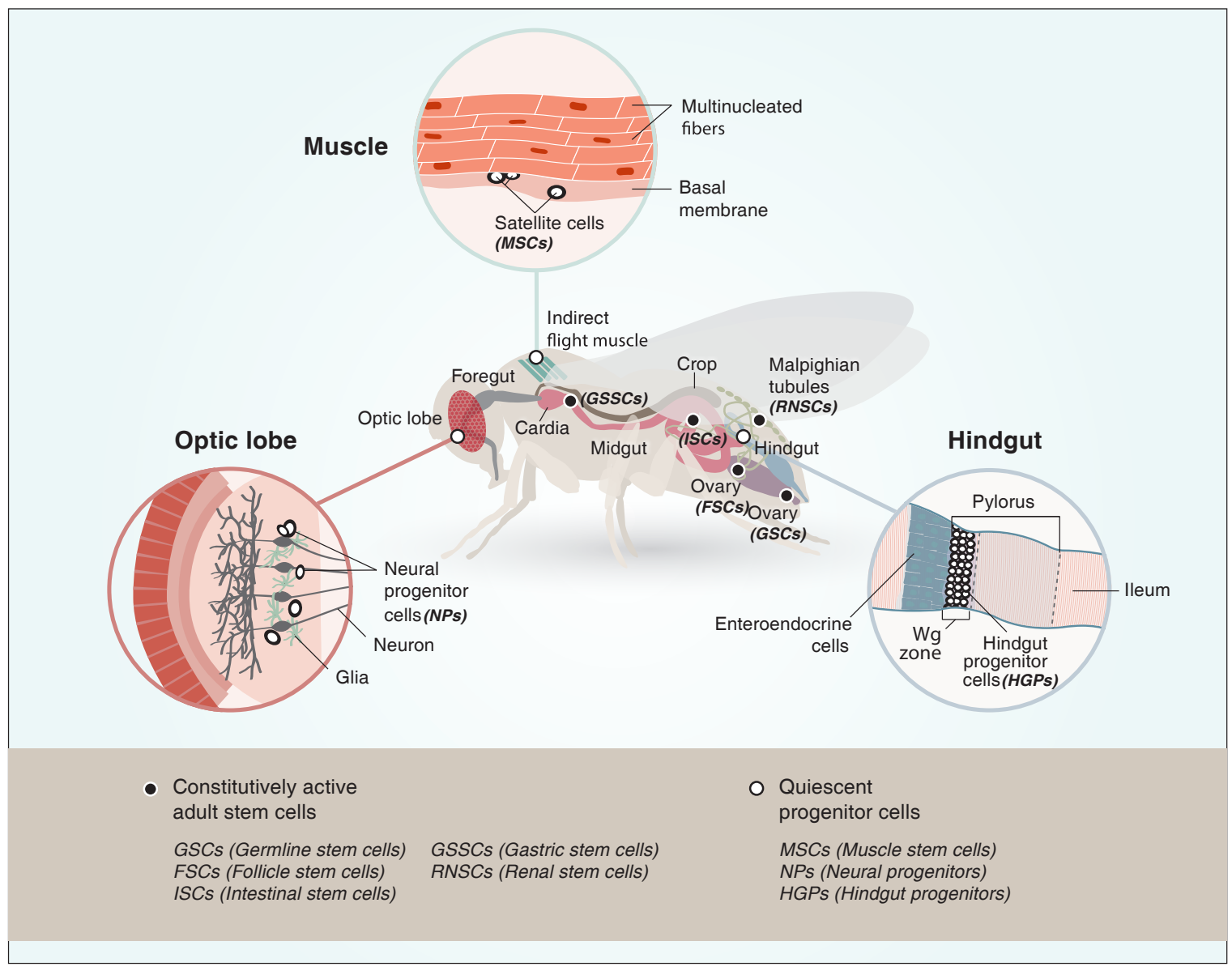

Fig. 1. Homeostatic and quiescent stem cells in Drosophila. Localization of known active (black dots) and quiescent adult stem/progenitor cells (white dots) in Drosophila melanogaster. OGSC, ovary germline stem cell; FCS, follicular stem cell; ISC, intestinal stem cell; GSSC, gastric stem cell; RNSC, renal stem cell; MSC, muscle stem cell; NP, neural progenitor; HGP, hindgut progenitor. 
ghian tubules (MTs) (Singh et al., 2007) (Fig. 1). Similarly to human kidneys, the MTs in the fly serve to eliminate waste products. They are composed of a long anterior and a short posterior pair of tubules, which converge through common ureters onto the posterior midgut. Lineage tracing experiments conducted by Singh and co-workers suggest that the lower tubules and ureters harbour multi-potent renal stem cells (RNSCs) (Fig. 1), which are actively dividing and stain positive for the mitotic markerPhospho-Histone 3(PH3). The progeny
A

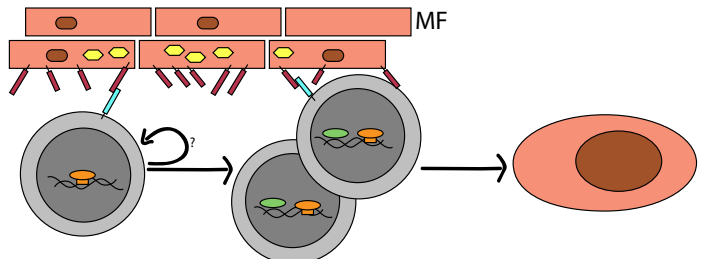

$\mathrm{OPH} 3=$ Delta $\bigcirc$ Neuralized

○Zfh1 $\rightleftharpoons$ Notch MF Multinucleated fibers
Satellite cells Activated satellite cells Mature muscle cell

\section{Skeletal muscle}

Type of injury

Stab lesion

Damage-induced processes

Proliferation of satellite cells ( $\mathrm{PH} 3)$

Upregulation of Delta and Neuralized

in injured fibers

\section{Putative niche}

Multinucleated fibers

Cell potency

Unipotent

\section{Hindgut}

B

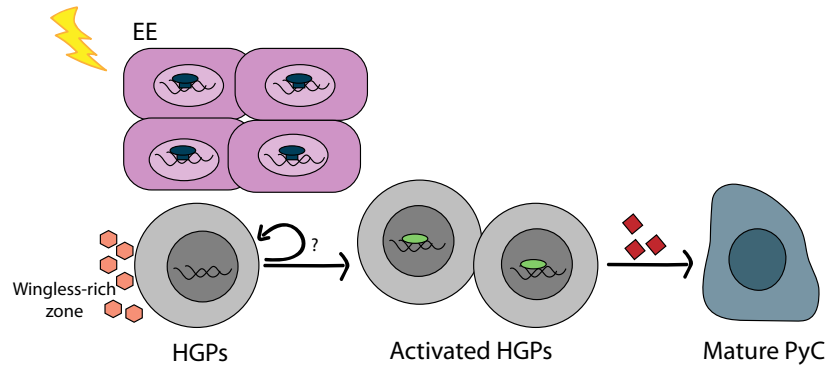

$\checkmark$ PH3 Hedgehog EE Enteroendocrine cells

$\checkmark$ Wingless Prospero HGPs Hindgut progenitors PyC Pyloric cell

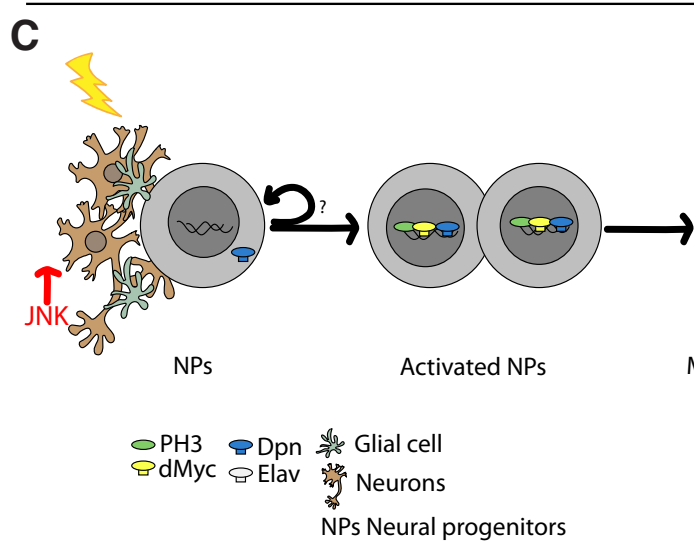

Type of injury

Apoptosis/chemical damage

Damage-induced processes

Proliferation of progenitor cells (PH3, BrdU)

\section{Putative niche}

Enteroendocrine cells (midgut)

Wingless-rich zone

\section{Cell potency}

Not fully defined yet

\section{Optic lobe}

Type of injury

Stab lesion

\section{Damage-induced processes}

Increased JNK activity

Proliferation of progenitor cells (PH3)

Upregulation of Dpn and dMyc in

progenitor cells

Mature Neuron

Putative niche

Neurons and glial cells

Cell potency

Unipotent

Fig. 2. Injury-induced proliferation of quiescent progenitors. Schematic representation of progeny derived from damage-responsive stem cells in muscle (A), hindgut (B) and optic lobes of the brain (C). (A) Damage to the dorso-ventral flight muscle leads to induction of Delta ligands on multinucleated muscle fibres and activates proliferation of underlying quiescent muscle stem cells, which will give rise to fusion-competent myoblasts. (B) Hindgut injury triggers division of putative hindgut stem cells (hindgut progenitors) and the generation of new cells in the pylorus. (C) Traumatic injury to the optic lobe leads to local activation of JNK and the upregulation of Drosophila $M y c(d M y c)$ in adult neural progenitor cells, which drives division.

Besides highly proliferative germline stem cells (GSCs), the germline additionally contains somatic (epithelial) stem cells. The follicular epithelium of the ovary is maintained by follicular stem cells (FSCs) (Fig. 1) FSCs constantly divide to generate polar cells, stalk cells and main body cells that wrap developing follicles (Nystul and Spradling, 2007). There are two FCSs per ovariole, which divide approximately every $10 \mathrm{~h}$ (Margolis and Spradling, 1995; Nystuland Spradling, 2007). Their proliferation rate is coordinated with the cycling of ovary GSCs at the ovariole tip (Fig. 1). FCSs are anchored to the basement membrane and have contact with neighboring escort cells (Nystul and Spradling, 2010), which may provide niche signals. Analogous to FCSs, cyst stem cells in the male germline continually proliferate to produce ensheathing cells for cysts, which subsequently develop into sperm cells (Gonczy and DiNardo, 1996; Amoyel et al., 2013).

\section{Damage-responsive quiescent stem cells}

In contrast to dividing stem cells, there is also experimental support for the existence of quiescent progenitors in various adult fly tissues. These inactive stem cells do not divide (or only minimally) in resting/homeostatic conditions, but switch to a proliferative mode upon tissue damage.

Mammalian muscle stem cells (MSCs), the satellite cells, represent a clear-cut example of quiescent, damage-responsivestem cells, which can remain dormantfor years and only become mitotic when muscle fibres are lesioned (Brack and Rando2012). Satellite cells are small stem cells that are located close to mature muscle fibres, formed by multinucleated fused musclecells. Surprisingly, adult MSCs had not been described in Drosophila until very recently, when Chaturvedi 
and colleagues closely examined the anatomy of the dorso-ventral muscle (DVM), an indirect flight muscle (Fig. 1). In close association with the DVM, they found small, unfused cells at the surface of multi-nucleated muscle cells, which were surrounded by the basal lamina of the muscle fibre (Chaturvedi et al., 2017) (Fig. 2). The DVM muscle is known to form by de novo fusion of myoblasts in pupal stages (Gunage et al., 2014), whereas other muscles in the fly are assembled differently. Chaturvedi et al., went on to show that the unfused non-dividing cells are lineal descendants of previously identified adult muscle progenitor cells (AMPs) (Dhanyasi et al., 2015), which still express the zinc finger transcription factor Zfh1, in contrast to adult muscle fibres (Chaturvedi et al., 2017). Stab lesions of the DVM efficiently triggered proliferation of Zfh1-positive cells, which resulted in the generation of fusion-competent myoblasts for muscle regeneration, as revealed by G-trace labelling (Chaturverdi et al., 2017). Based on morphology and function, the unfused Zhf1expressing cells in the DVM muscle represent the equivalent of mammalian satellite cells in Drosophila. These findings highlight a case of astonishing similarity between damage-responsive satellite cells in flies and vertebrates.

How are satellite cells activated in response to injury? Chaturvedi and colleagues found that mechanical damage triggers 1 . the massive upregulation of Delta ligands on injured muscle fibres and 2. leads to the induction of Neuralized, an E3 ubiquitin ligase, which positively regulates Notch signalling (Lai et al., 2001) (Fig. 2). The injury-induced Delta expression on muscle cells is crucial to trigger proliferation of underlying satellite cells expressing Notch since knock-down of Delta in adult muscle strongly suppresses mitotic activity of MSCs (Chaturverdi et al., 2017).

Previously, in2009, Fox and Spradling provided evidence suggesting that the adult hindgut may harbour putative damage-responsive stem cells (Fig. 1). The hindgut consists of the pylorus, which functions as a valve, the ileum and the rectum. Although an initial study described the presence of cycling stem cells at the midgut/hindgut border (Takashima et al., 2008), re-examination with improved linage tracing tools and BrdU incorporation experiments uncovered that there is little proliferation and no homeostatic cell turnover in the unstressed adult hindgut (Fox and Spradling, 2009). However, Fox and Spradling showed that Wg-positive cells within the anterior pylorus can divide following tissue injury caused by induction of proapoptotic genes or chemicals. Upon damage, BrdU incorporation was first observed within a stripe of Wg-expressing cells at the anterior end, followed by cells further downstream in the pylorus. Based on these findings, the $\mathrm{Wg}$-rich zone in the pylorus has been proposed to contain damage-responsive hindgut progenitor cells (HGPs) (Figs. 1 and 2). The Hedgehog pathway was also suggested to play a role in differentiation of HGPs, although these initial experiments have to be revisited using alternative tracing methods (Takashima et al., 2008). The damage-induced proliferation in the hindgut may also represent the result of cell dedifferentiation in this region, followed by cell division. The identification of more specific markers might shed more light on the possible stem cell nature of cells in the pylorus.

Another enigmatic, largely quiescent progenitor type has been recently detected in the optic lobes of the adult fly brain (FernándezHernández et al., 2013) (Fig. 1). In Drosophila, a deep understanding of neural stem cell proliferation has been gained by studying the proliferation and differentiation of different types of neuroblasts, which generate the high diversity of nerve cells in the course of nervous system development (Homem et al., 2015; Kang and
Reichert, 2015; Doe, 2017). The adult Drosophila brain, in turn, was believed to lack neurogenic activity compared to apparent neurogenesis in central brain regions of other insects (Simões and Rhiner, 2017). Only the combination of brain injury (stab lesions) and highly sensitive mitotic-dependent lineage tracing resulted in a clearly observable proliferative response in the optic lobes of the adult brain (Fernández-Hernández et al., 2013). Further analyses revealed that the regenerated tissue after injury consisted mainly of newly formed neurons. These adult-born neurons do not derive from dedifferentiation of glial cells, but rather from neuroblast-like adult progenitors (NPs) scattered throughout the optic lobes. As key features, NPs contain a large nucleus and show expression of the Zn-finger transcription factor Deadpan (Dpn) (Bier et al., 1992), a marker of larval neuroblasts. Dpn belongs to a family of transcription factors similar to human HES-1. In larval neuroblasts, Dpn has been shown to bind to promoter regions of cyclin E (Southall and Brand, 2009), which is important for cell cycle regulation. Mechanical injury of optic lobes leads to rapid and local induction of JNK stress signalling in neurons and glia close to the stab lesion (Moreno et al., 2015) and the upregulation of dMyc in NPs (Fernández-Hernández et al., 2013) (Fig. 2). In fact, a short pulse of dMyc overexpression can provoke NP expansion even in the absence of injury (FernándezHernández et al., 2013).

Although neuroblasts give rise to both glia and neurons during development, adult NPs appear to form only neurons following injury. The newly generated nerve cells have been monitored for up to several weeks after injury. They show very robust survival and send out long axonal processes to correct target areas, indicating appropriate maturation (Moreno et al., 2015; Fernández-Hernández et al., 2013). In order to further characterize the regenerative neurogenesis, it will be important to study if adult-born neurons gain functionality and to what extent they may contribute to possible recovery of brain functions after injury in the fly. The latter will strongly depend on the development of tools to specifically suppress regenerative neurogenesis and the set-up of sophisticated behavioural assays. In the absence of acute brain damage, NPs have also been found to contribute to low-level adult neurogenesis in the optic lobes (Fernández-Hernández et al., 2013), the significance of which is not understood. Regenerative neurogenesis has so far only been observed in the optic lobes. If damage-responsive progenitors are also functional in the central brain remains to be explored. Future work may also clarify if injury-induced cytokines or morphogens play a role in neural progenitor activation. RNAi screening approaches should allow the identification of key regulators of damage-induced NP activation and may potentially uncover mechanisms that may be important to boost efficient regenerative neurogenesis in humans with limited regenerative capacity in the brain.

The inducible proliferation of the above-described quiescent progenitors is reminiscent of damage-responsive reserve stem cells described in mammals (Visvader et al., 2016). Although the maintenance of inactive stem cells is associated with an energetic cost, they seem to provide an evolutionarily successful safeguard mechanism to protect organismal integrity.

\section{Conclusions}

The recent discovery of somatic stem cells in adult tissues of Drosophila melanogaster has paved the way to not only delve into homeostatic stem cell regulation, but also damage-induced 
proliferation. However, we still lack a detailed understanding of how damage cues influence stem cell regulation and if injury-induced signals can trigger regeneration via mechanisms that are distinct from reactivation or enforcement of developmental or homeostatic processes. Studies in mammals provide evidence that mechanisms driving stem cell proliferation upon injury may at least be partially distinct from those controlling tissue homeostasis (Cai et al., 2010), a notion that has also emerged from the above-discussed fly studies.

Improved lineage tracing tools and the increasing interest in stem cell biology have successfully led to the identification of numerous adult somatic stem cells in Drosophila. The advanced genetic toolbox and the ease of genetic analyses in the fruit fly should provide key advantages to deepen our molecular understanding of how quiescent damage-responsive progenitors can be activated and instructed for efficient repair.

\section{Acknowledgements}

We thank Gil Costa for the artwork in Figure 1 and Anna Hobbiss for comments on the manuscript. This work has been supported by the Champalimaud Foundation.

\section{References}

AMOYEL ML, SANNY J, BUREL M, BACH EA (2013). Hedgehog is required for CySC self-renewal but does not contribute to the GSC niche in the Drosophila testis. Development 1: 56-65.

BIER E, VAESSIN H, YOUNGER-SHEPHERD S, JAN LY, JAN YN (1992). Deadpan, an essential pan-neural gene in Drosophila, encodes a helix-loop-helix protein similar to the hairy gene product. Genes Dev 6: 2137-2151.

BITEAU B, HOCHMUTH CE, JASPER H (2008). JNK activity in somatic stem cells causes loss of tissue homeostasis in the aging Drosophila gut. Cell Stem Cell 3: 442-455.

BOSCH M, SERRAS F, MARTÍN-BLANCO E, BAGUÑÀ J (2005). JNK signaling pathway required for wound healing in regenerating Drosophila wing imaginal discs. Dev Biol 280: 73-86.

BRACK AS, RANDO TA (2012). Tissue-specific stem cells: lessons from the skeletal muscle satellite cell. Cell Stem Cell 5: 504-514.

CAI J, ZHANG N, ZHENG Y, DE WILDE RF, MAITRA A, PAN D (2010). The Hippo signaling pathway restricts the oncogenic potential of an intestinal regeneration program. Genes Dev 21: 2383-2388.

CHATURVEDI D, REICHERT H, GUNAGE RD, VIJAYRAGHAVAN K (2017). Identification and functional characterization of muscle satellite cells in Drosophila. Elife 6: e30107.

CHENG T, RODRIGUES N, SHEN H, YANG Y, DOMBKOWSKI D, SYKES M, SCADDEN DT (2000). Hematopoietic stem cell quiescence maintained by p21cip1/ waf1. Science 287:1804-1808.

CHEUNG TH, RANDO TA (2013). Molecular regulation of stem cell quiescence. Nat Rev Mol Cell Biol 6: 329-340.

CORDERO JB, STEFANATOS RK, SCOPELLITI A, VIDAL M, SANSOM OJ (2012). Inducible progenitor-derived Wingless regulates adult midgut regeneration in Drosophila. EMBO J 19: 3901-3917.

DHANYASI N, SEGAL D, SHIMONI E, SHINDER V, SHILO BZ, VIJAYRAGHAVAN K, SCHEJTER ED (2015). Surface apposition and multiple cell contacts promote myoblast fusion in Drosophila flight muscles. J Cell Biol 1: 191-203.

DOE CQ (2017). Temporal Patterning in the Drosophila CNS. Annu Rev Cell Dev Biol 33: 219-240.

DUTTA D, DOBSON AJ, HOUTZ PL, GLÄßER C, REVAH J, KORZELIUS J, PATEL PH, EDGAR BA, BUCHON N (2015). Regional Cell-Specific Transcriptome Mapping Reveals Regulatory Complexity in the Adult Drosophila Midgut. Cell Rep 12: 346-358.

FERNÁNDEZ-HERNÁNDEZ I, RHINER C, MORENO E (2013). Adult neurogenesis in Drosophila. Cell Rep 6: 1857-1865

FOGARTYCE, DIWANJI N, LINDBLAD JL, TAREM, AMCHESLAVSKYA, MAKHIJANI
K, BRÜCKNER K, FAN Y, BERGMANN A (2016). Extracellular Reactive Oxygen Species Drive Apoptosis-Induced Proliferation via Drosophila Macrophages. Curr Biol 26: 575-584.

FOX DT, SPRADLING AC (2009). The Drosophila hindgut lacks constitutively active adult stem cells but proliferates in response to tissue damage. Cell Stem Cell 3: 290-297.

FUCHS E, CHEN T (2013). A matter of life and death: self-renewal in stem cells. EMBO Rep 14: 39-48.

FULLER MT AND SPRADLING AC (2007). Male and female Drosophila germline stem cells: two versions of immortality. Science 316: 402-404.

GONCZY P, DINARDO S (1996). The germ line regulates somatic cyst cell proliferation and fate during Drosophila spermatogenesis. Development 122: 2437-2447.

GREENSPAN LJ, DE CUEVAS M, MATUNIS E (2015). Genetics of gonadal stem cell renewal. Annu Rev Cell Dev Biol 31: 291-315.

GUNAGE RD, REICHERT H, VIJAYRAGHAVAN K (2014). Identification of a new stem cell population that generates Drosophila flight muscles. Elife 3: e03126.

GUO Z, LUCCHETTA E, RAFEL N, OHLSTEIN B (2016). Maintenance of the adult Drosophilaintestine: all roads lead to homeostasis. Curr Opin GenetDev 40:81-86.

HOCHMUTH CE, BITEAU B, BOHMANN D, JASPER H (2011). Redox regulation by Keap1 and Nrf2 controls intestinal stem cell proliferation in Drosophila. Cell Stem Cell 4;8: 188-99.

HOMEM CC, REPIC M, KNOBLICH JA (2015). Proliferation control in neural stem and progenitor cells. Nat Rev Neurosci 16: 647-659.

HUDRY B, KHADAYATE S, MIGUEL-ALIAGA I (2016). The sexual identity of adult intestinal stem cells controls organ size and plasticity. Nature 7590: 344-348.

ITO M, LIU Y, YANG Z, NGUYEN J, LIANG F, MORRIS RJ, COTSARELIS G (2005). Stem cells in the hair follicle bulge contribute to wound repair but not to homeostasis of the epidermis. Nat Med 11: 1351-1354.

JIANG H, PATEL PH, KOHLMAIER A, GRENLEY MO, MCEWEN DG, EDGAR BA (2009). Cytokine/Jak/Stat signaling mediates regeneration and homeostasis in the Drosophila midgut. Cell 137: 1343-1355.

KAIT, SPRADLING A (2004). Differentiating germ cells can revert into functional stem cells in Drosophila melanogaster ovaries. Nature 6982: 564-569.

KANG KH, REICHERT H (2015). Control of neural stem cell self-renewal and differentiation in Drosophila. Cell Tissue Res 1: 33-45.

LAI EC, DEBLANDRE GA, KINTNER C, RUBIN GM (2001). Drosophila neuralized is a ubiquitin ligase that promotes the internalization and degradation of delta. Dev Cell 6: 783-794.

LEE KA, KIM SH, KIM EK, HA EM, YOU H, KIM B, KIM MJ, KWON Y, RYU JH, LEE WJ (2013). Bacterial-derived uracil as a modulator of mucosal immunity and gut-microbe homeostasis in Drosophila. Cell 153: 797-811.

LEUSHACKE M, TAN SH, WONG A, SWATHI Y, HAJAMOHIDEEN A, TAN LT, GOH J, WONG E, DENIL SLIJ, MURAKAMI K, BARKER N (2017). Lgr5-expressing chief cells drive epithelial regeneration and cancer in the oxyntic stomach. Nat Cell Biol 7: 774-786.

LOSICK VP, FOXDT, SPRADLING AC (2013). Polyploidization and cell fusion contribute to wound healing in the adult Drosophila epithelium. Curr Biol 22: 2224-2232.

LOSICK VP, JUN AS, SPRADLING AC (2016). Wound-Induced Polyploidization: Regulation by Hippo and JNK Signaling and Conservation in Mammals. PLoS One 11: e0151251.

LU CP, POLAK L, ROCHAAS, PASOLLI HA, CHEN SC, SHARMA N, BLANPAIN C, FUCHSE (2012). Identification of stem cell populations in sweat glands and ducts reveals roles in homeostasis and wound repair. Cell 150:136-150.

MARGOLIS J, SPRADLING AC (1995). Identification and behavior of epithelial stem cells in the Drosophila ovary. Development 121: 3797-3807.

MICCHELLI C, PERRIMON N (2006). Evidence that stem cells reside in the adult Drosophila midgut epithelium. Nature 439: 475-479.

MORENO E, FERNANDEZ-MARREROY, MEYER P, RHINER C (2015). Brain regeneration in Drosophilainvolves comparison of neuronal fitness. Curr Biol7: 955-963.

NÁSZAI M, CARROLL LR, CORDERO JB (2015). Intestinal stem cell proliferation and epithelial homeostasis in the adult Drosophila midgut. Insect Biochem $\mathrm{Mol}$ Biol 67: 9-14.

NYSTULT, SPRADLING A (2007). An epithelial niche in the Drosophila ovary undergoes long-range stem cell replacement. Cell Stem Cell 1: 277-285. 
NYSTUL T, SPRADLING A (2010). Regulation of epithelial stem cell replacement and follicle formation in the Drosophila ovary. Genetics 2: 503-515.

OHLSTEIN B, SPRADLING AC (2006). The adult Drosophila posterior midgut is maintained by pluripotent stem cells. Nature 439: 470-474.

POSS KD (2010). Advances in understanding tissue regenerative capacity and mechanisms in animals. Nat Rev Genet 10: 710-722.

RAFF M (2003). Adult stem cell plasticity: fact or artifact? Annu Rev Cell Dev Biol 19: 1-22.

SÁNCHEZ ALVARADO A AND TSONIS PA (2006). Bridging the regeneration gap: genetic insights from diverse animal models. Nat Rev Genet 11: 873-884.

SANTABÁRBARA-RUIZ P, LÓPEZ-SANTILLÁN M, MARTÍNEZ-RODRÍGUEZ I, BINAGUI-CASAS A, PÉREZ L, MILÁN M, COROMINAS M, SERRAS F (2015). ROS-induced JNK and p38 signaling is required for unpaired cytokine activation during Drosophila regeneration. Plos Genet 11: e1005595.

SMITH-BOLTON RK, WORLEY MI, KANDA H, HARIHARAN IK (2009). Regenerative growth in Drosophila imaginal discs is regulated by Wingless and Myc. Dev Cell 16: 797-809.

SIMÕES AR, RHINER C (2017). A Cold-Blooded view on adult neurogenesis. Front Neurosci 11: 327

SINGH SR, LIU W, HOU SX (2007). The adult Drosophila malpighian tubules are maintained by multipotent stem cells. Cell Stem Cell 2: 191-203.

SINGH SR, ZENG X, ZHENG Z, HOU SX (2011). The adult Drosophila gastric and stomach organs are maintained by a multipotent stem cell pool at the foregut/ midgut junction in the cardia (proventriculus). Cell Cycle 7: 1109-1120.

SOUTHALL TD, BRAND AH (2009). Neural stem cell transcriptional networks highlight genes essential for nervous system development. EMBO J 28: 3799-807.

SUH HN, KIM MJ, JUNG YS, LIEN EM, JUN S, PARK JI (2017). Quiescence Exit of Tert ${ }^{+}$Stem Cells by Wnt/ $\beta$-Catenin Is Indispensable for Intestinal Regeneration.
Cell Rep 21: 2571-2584.

TAKASHIMA S, MKRTCHYAN M, YOUNOSSI-HARTENSTEIN A, MERRIAM JR HARTENSTEIN V (2008). The behaviour of Drosophila adult hindgut stem cells is controlled by Wnt and Hh signalling. Nature 7204: 651-655.

TAKUBO K, GODAN, YAMADAW, IRIUCHISHIMAH, IKEDAE, KUBOTAY, SHIMAH JOHNSON RS, HIRAO A, SUEMATSU M, SUDAT (2010). Regulation of the HIF1 alpha level is essential for hematopoietic stem cells. Cell Stem Cell 7: 391-402.

TAMORI Y, DENG WM (2013). Tissue repair through cell competition and compensatory cellular hypertrophy in postmitotic epithelia. Dev Cell 4: 350-363.

TIAN H, BIEHSB, WARMING S, LEONG KG, RANGELLL, KLEIN OD, DE SAUVAGE FJ (2011). A reserve stem cell population in small intestine renders Lgr5-positive cells dispensable. Nature 7368: 255-259.

VISVADER JE, CLEVERS H (2016). Tissue-specific designs of stem cell hierarchies. Nat Cell Biol 18: 349-355.

WILSON A, LAURENTI E, OSER G, VAN DER WATH RC, BLANCO-BOSE W, JAWORSKI M, OFFNER S, DUNANT CF, ESHKIND L, BOCKAMP E, LIÓ P, MACDONALD HR, TRUMPPA(2008). Hematopoietic stem cells reversibly switch from dormancy to self-renewal during homeostasis and repair. Cell 6: 1118-1129.

YAN KS, CHIA LA, LI X, OOTANI A, SU J, LEE JY, SU N, LUO Y, HEILSHORN SC, AMIEVA MR, SANGIORGI E, CAPECCHI MR, KUO CJ (2012). The intestinal stem cell markers Bmi1 and Lgr5 identify two functionally distinct populations. Proc Natl Acad Sci USA 2: 466-471.

XU C, LUO J, HE L, MONTELL C, PERRIMON N (2017). Oxidative stress induces stem cell proliferation via TRPA1/RyR-mediated $\mathrm{Ca} 2+$ signaling in the Drosophila midgut. eLife $31 ; 6$. pii: e22441.

ZHAI Z, BOQUETE JP, LEMAITRE B (2017). A genetic framework controlling the differentiation of intestinal stem cells during regeneration in Drosophila. PLOS Genet 6: e1006854. 


\section{Further Related Reading, published previously in the Int. J. Dev. Biol.}

Recent advances in Drosophila stem cell biology

John Pearson, Lourdes López-Onieva, Patricia Rojas-Ríos and Acaimo González-Reyes

Int. J. Dev. Biol. (2009) 53: 1329-1339

https://doi.org/10.1387/ijdb.072431jp

Origin and proliferation of blastema cells during regeneration of Drosophila wing imaginal discs

Manel Bosch, Jaume Baguñà and Florenci Serras

Int. J. Dev. Biol. (2008) 52: 1043-1050

Genetic control of dorsoventral patterning and neuroblast specification in the Drosophila Central Nervous System

Guoyan Zhao, Scott R. Wheeler and James B. Skeath

Int. J. Dev. Biol. (2007) 51: 107-115

https://doi.org/10.1387/ijdb.062188gz

Role of Jun N-terminal Kinase (JNK) signaling in the wound healing and regeneration of a Drosophila melanogaster wing imaginal disc

Jaakko Mattila, Leonid Omelyanchuk, Satu Kyttälä, Heikki Turunen and Seppo Nokkala Int. J. Dev. Biol. (2005) 49: 391-399

APC dosage effects in tumorigenesis and stem cell differentiation

Claudia Gaspar and Riccardo Fodde

Int. J. Dev. Biol. (2004) 48: 377-386

http://www.intjdevbiol.com/web/paper/041807cg

5 yr ISI Impact Factor $(2016)=2.421$
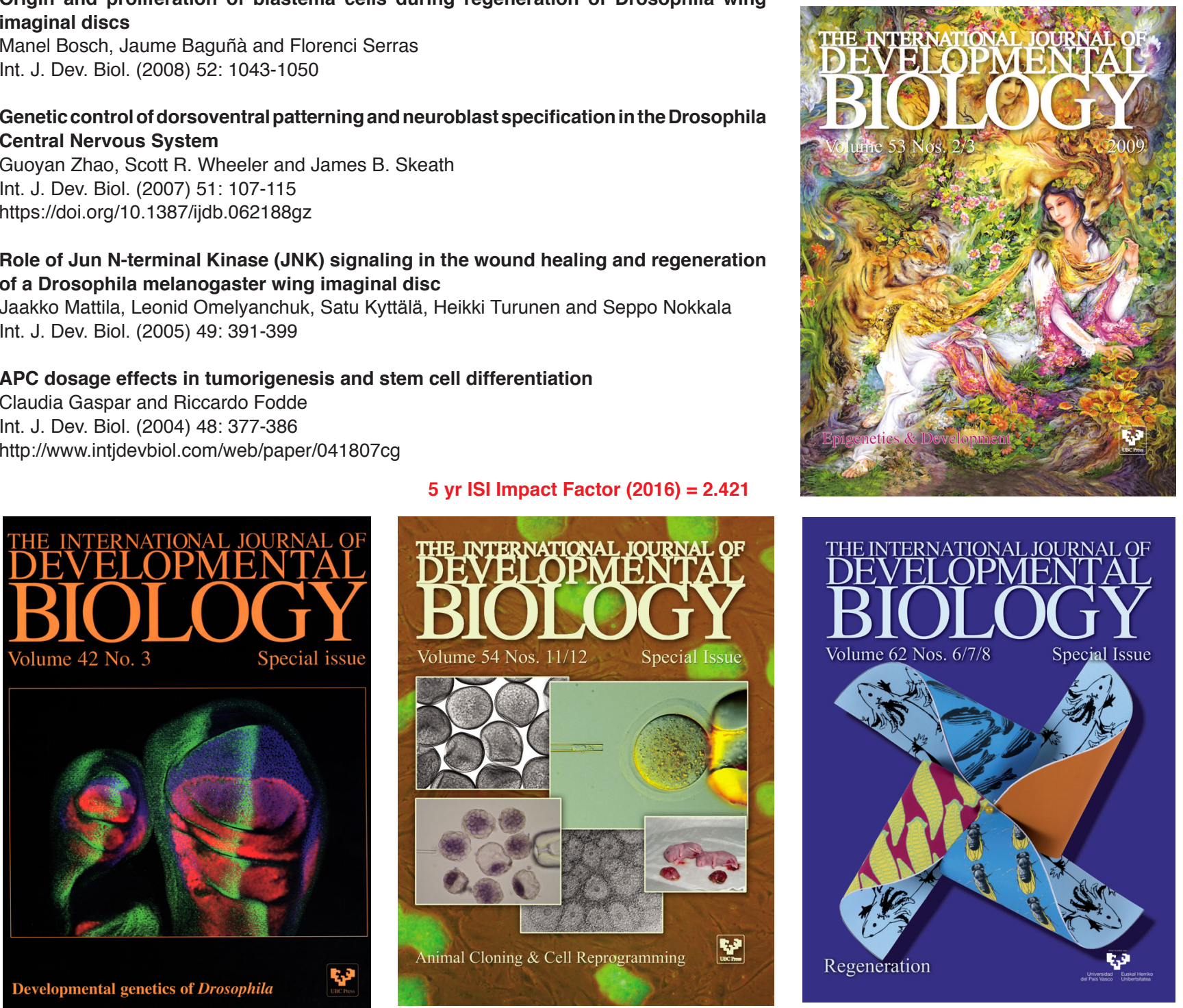